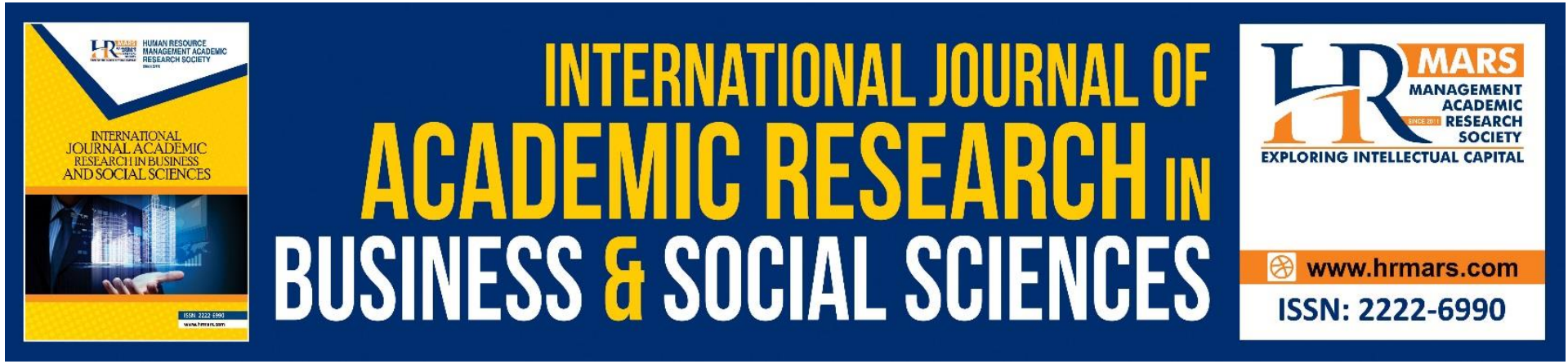

\title{
A Thematic Analysis of Online Learning Experiences Among Students of a Language Programme: Instructors' Delivery and Peer Interaction
}

Ahmad Harith Syah Md Yusuf, Sumarni Maulan, JF, Hoo, Adi Idham Jailani, Norazlina Mohamad Ayob

To Link this Article: http://dx.doi.org/10.6007/IJARBSS/v11-i6/10387

DOI:10.6007/IJARBSS/v11-i6/10387

Received: 15 April 2021, Revised: 18 May 2021, Accepted: 30 May 2021

Published Online: 16 June 2021

In-Text Citation: (Yusuf et al., 2021)

To Cite this Article: Yusuf, A. H. S. M., Maulan, S., JF, H., Jailani, A. I., \& Ayob, N. M. (2021). A Thematic Analysis of Online Learning Experiences Among Students of a Language Programme: Instructors' Delivery and Peer Interaction. International Journal of Academic Research in Business and Social Sciences, 11(6), 1602-1611.

Copyright: @ 2021 The Author(s)

Published by Human Resource Management Academic Research Society (www.hrmars.com)

This article is published under the Creative Commons Attribution (CC BY 4.0) license. Anyone may reproduce, distribute, translate and create derivative works of this article (for both commercial and non-commercial purposes), subject to full attribution to the original publication and authors. The full terms of this license may be seen at: http://creativecommons.org/licences/by/4.0/legalcode

Vol. 11, No. 6, 2021, Pg. 1602 - 1611

Full Terms \& Conditions of access and use can be found at http://hrmars.com/index.php/pages/detail/publication-ethics 


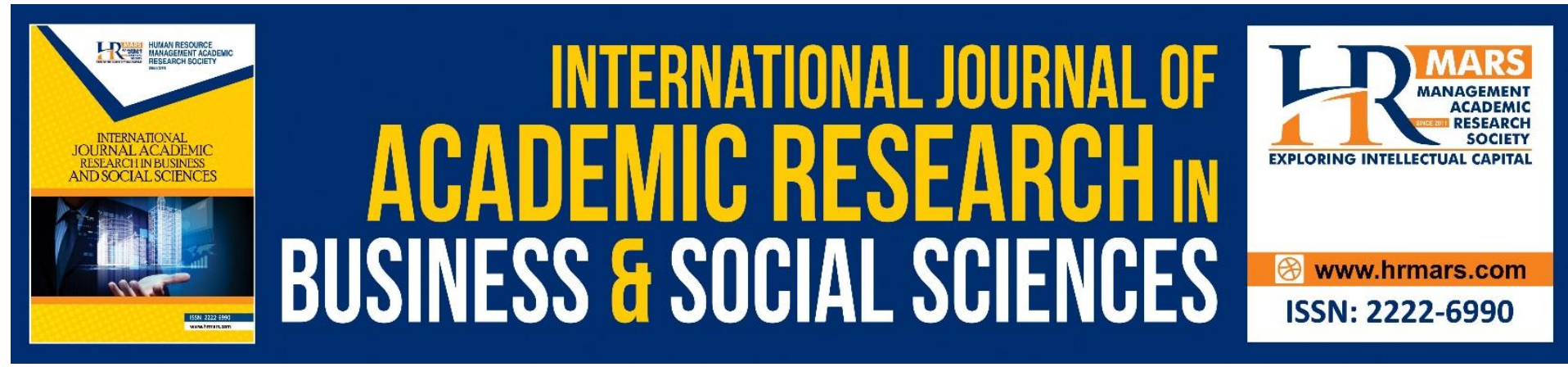

\title{
A Thematic Analysis of Online Learning Experiences Among Students of a Language Programme: Instructors' Delivery and Peer Interaction
}

\author{
Ahmad Harith Syah Md Yusuf, Sumarni Maulan, JF, Hoo, Adi \\ Idham Jailani, Norazlina Mohamad Ayob \\ Universiti Teknologi MARA, Alor Gajah, Melaka, Malaysia \\ Email: harith424@uitm.edu.my
}

\begin{abstract}
The Fully Online Learning Community (FOLC) framework was authored by Van Oostveen (2016) based on a social constructivism theory that proposes all knowledge develops as a result of social interaction. Amid Covid-19 pandemic, students and instructors alike are forced to be part of this community of which their experiences with 'social presence' are crucial to inform curriculum designers the efficacy of online learning curriculum, Thus, this paper aims to look into the online learning experiences among a group of students of a language programme particularly on their social involvement: instructor's delivery and peer interaction. A six-stage thematic analysis (TA) (Braun \& Clark, 2006) was used to code the data from 256 respondents of an open-ended questionnaire. A total of 11 recurring themes were found for instructors' delivery: platform, material, delivery technique, interaction, support, feedback, live session duration, availability, instructors' characteristics, mode suitability and materials accessibility. However only six themes were coded for peer interaction: activities, support, mode suitability, platform, cooperation, and the Internet connectivity. These themes correspond with seven of the nine dimensions of online learning design proposed by Means, Bakia and Murphy (2014) which are modality, pacing, instructor role online, student role online, online communication synchrony, pedagogy, and source of feedback. In conclusion, TA is useful in informing curriculum designers and instructors to improve the existing online learning curriculum and practices while the students can benefit to become better learners in online learning.
\end{abstract}

Keywords: Thematic Analysis, Online Language Learning Experience, Instructor's Delivery, Peer Interaction

\section{Introduction}

The notion of traditional education has changed radically within the last couple of years and it is known that being physically present in a classroom is not the only learning option anymore, not with the rise of the internet and new technologies, and now with the coronavirus pandemic, it has become more important than ever. Nowadays, students have 
access to a quality education whenever and wherever they want if they have access to a computer. It is laborious to understand the notion of leaving behind the conventional classroom, but it is a must to understand the crucial situation to adopt and adapt to new learning options. The revolution of online education is the new era.

Due to the recent Covid-19 pandemic that has hit the world hard, all education sectors have been greatly affected. Malaysia is not spared from this situation too. The Malaysian government is also working hard in controlling the spread of the virus by enforcing Movement Control Order (MCO), policies, guidelines, and restrictions to all sectors, as well as education (Chung, Noor \& Mathew, 2020). Precautionary steps were taken, and these have affected the teaching and learning process for the past one year. Universities were told to close during the first phase of MCO and they are still not opened for physical class implementation until today. However, it is deemed that education is still an important sector that must be continued despite all challenges and barriers faced. In response to the government's actions and the self-initiatives of the universities' management in the country, the education sector could only agree that technology is the only way forward. Academic interests are not disregarded, and educators are motivated and encouraged to strive hard to provide teaching and learning activities while implementing Open and Distance Learning (ODL) with any available methods, tools and means.

Classrooms walls are no longer a barrier as technology enables new ways of learning, communicating, and working collaboratively. Schools and universities across the country are beginning to redesign learning spaces to enable this new norm of education, fostering more interaction with the use of technology as an enabler. Access to learning opportunities today is unprecedented in scope thanks to technology.

Nevertheless, it is important to have a good online learning curriculum to standardise learning goals for educational institutions to ensure students are able to progress and continue learning consistently. With the accelerated rate of social change, "social presence" in online learning could well enhance learners'-instructors' interactions and improve learners' activities as well as enhance learners' experience. It will be up to instructional designers and educational technologies to make the most of the opportunities provided by technology to change education so that effective and efficient education is available to everyone everywhere.

Thus, this paper aims to investigate the online learning experiences among a group of students of a language programme on their social involvement specifically focusing on instructor's delivery and peer interaction. Thematic analysis is used to identify online learning system needs and to develop plans to address ineffectiveness in a language program curriculum using quality improvement initiatives with best evidence. In collaboration with knowledge users and decision makers, curriculum designers aimed to understand what made these networks effective, including how networks engaged their stakeholders and what knowledge translation and engagement looked like across these initiatives.

\section{Literature Review}

\section{Open and Distance Learning}

Driven by United Nations Educational, Scientific and Cultural Organization's (UNESCO) 4th Sustainable Development Goals (SDG) that is to provide quality education for all, many universities are motivated to move towards that direction. Over the years, Universiti Teknologi MARA (UiTM) has persevered to digitalise education by leveraging on the fourth Industrial Revolution (4IR). It aims at revolutionising education to deliver a good quality 
education that is integrated with technology and data driven technique. With the COVID-19 pandemic as the all-powerful factor to redefine cultural shift of traditional classroom to Open and Distance Learning (ODL) for Higher Education Institutions (HEIs) and across the world, the lockdown and Movement Control Order (MCO) imposed by countries have then been the real culprits for universities to materialise a valid and practical teaching and learning process to promote the continuation of education for learners.

\section{Thematic Analysis}

Thematic analysis (TA) is a commonly used qualitative data analysis approach in psychology (Braun \& Clarke, 2006), health care (Braun \& Clarke, 2014), sport and exercise (Braun et al., 2017), and many other fields (Boyatzis, 1998). TA is helpful in analysing a rich set of data collected from any studies conducted.

The study aims to articulate and demonstrate TA as an accessible and flexible method to analyse qualitative data collected in the natural classroom setting from an instructorresearcher perspective. In addition to detailing the steps of conducting TA as other practical examples have undertaken (Braun \& Clarke, 2006; Fereday \& Muir-Cochrane, 2006; Nowell et al., 2017), this study has its strength in outlining multiple data collection tools and their associated analytical processes. Such diverse data sources are flexible enough to accommodate the natural classroom and provide sensitive and rich descriptions of the educational phenomenon specifically for ODL purposes. The steps of analysing them are instrumental in enhancing instructor-researchers' capability of carrying out theoretically and methodologically sound analysis.

TA involves finding repeated meanings across a data set, which is crucial to the interpretation of phenomena (Vaismoradi et al., 2013). A theme refers to a specific pattern found that captures some crucial information about the data in relation to the research questions and features patterned meanings across the data set (Braun \& Clarke, 2006). It pertains to a shared topic regarding area of focus rather than summaries of data domains (Braun \& Clarke, 2019). The terms "pattern" and "theme" are used interchangeably in the literature, and in this study, "theme" will be consistently used.

\section{Fully Online Learning Community (FOLC)}

Fully Online Learning Community (FOLC) which was advocated by Van Oostveen (2016) based on a social constructivism theory proposes that all knowledge is developed because of social interaction. The FOLC model comprises two dimensions namely Social Presence (SC) and Cognitive Presence (CP) in which these two synergise primarily within a Digital Space that is made up of community-selected, synchronous, and asynchronous affordances.

The language programme involved in the study is designed to tap the professional communication skills that involves a lot of social engagement; hence this model was used as the foundation of this paper. This research focuses on the 'social presence' in the model with the instructors and peers as the selected community within the 'digital space' that exists in the online learning practice for the programme.

The social presence in this study specifically referring to the instructors and learners. Digital space indicates the platforms chosen for Teaching and Learning. Intersections touch on the events, the teaching and learning that took place among the community within the digital space. In short, this study delves into how students perceive their instructors' delivery and peer interaction. 


\section{Research Objectives}

Thematic Analysis is useful in informing curriculum designers and instructors to improve the existing online learning curriculum and practices while the students can benefit to become better learners in online learning. The paper aims to analyse the online learning experiences among a group of students in LG120 Diploma in English for Professional Communication program particularly on their social involvement with the following research questions as follows:

1. How did students perceive instructors' delivery in their online learning experience?

2. How did students perceive peer interaction in their online learning experience?

The pandemic has given a whole new experience to students in their learning environment (Adnan \& Anwar, 2020). There is a need to draw up descriptions of core attributes to provide educators, and those responsible for training them, with clear goals and understanding of the role of an educator. Besides that, peer interaction is also conceived as paramount to ensure collaborative learning is adequately practiced throughout the process of teaching and learning in an ODL experience.

\section{Methodology}

To study the implementation of ODL, the study adopted a qualitative approach where the data was collected using a survey form. An online survey was conducted to all the 5 semesters of LG 120 students. 256 respondents from a total of 320 LG120 students have answered the end-of-semester open-ended courses survey consisting of four dimensions which consists of content, assessment, lecturers' delivery, and peer interaction. A six-stage thematic analysis by Braun \& Clark (2006) was employed to determine the themes.

The first stage was to identify and familiarise with data from the responses collected. Data were divided into the two dimensions investigating the instructors' delivery and peer interaction. Data were also cleaned from repetitive submission.

The second stage was to generate the initial codes. The distribution of positive, negative, and neutral responses and responses that were not applicable in any two dimensions were identified. Based on the inductive analysis of the data, the researchers had highlighted the keywords in the responses and familiarise with the recurring keywords.

The next stage was to examine themes. Theories, frameworks, and models pertaining to thematic analysis were interpreted as to which best represent the data. Relationships among data were also established between the themes.

The fourth stage was to review the themes to ensure that themes decided were checked for the data set and represented all the data coded in stage 2 .

The fifth stage was to identify the 11 themes for the instructors' role and 6 themes for the peer interaction.

The sixth and the last stage was to produce the report; the descriptive reporting of the data that brings us to the finding and discussion of this study. This paper thus will be reporting using descriptive data analysis for the findings and discussion of the study that was conducted. 


\section{Results and Discussions \\ Modality}

The first dimension of the online learning design that corresponds with the findings is modality. Modality refers to how instructors' delivery and peer interaction take place for example, fully online, blended or web enabled F2F.

"Through delivery, I do believe that it is also one of the subjects that in no need of face to face contact lectures as this new learning method does not the change the purpose of delivering the subject to us students. Nevertheless I understood every lesson that were introduced to us regarding the situation that we're currently in."

This response showed that the student believes that the course is suitable for fully online learning.

Another response quoted is:

"I believe that the delivery was purely understandable, coming from the subject itself as it did not require a mass amount of physical interaction with the lecturer. We were comfortable enough to express ourselves through online and the subject truly complimented the purpose of open and distance learning method."

Another student also shared the same thought about whether the course is suitable for online learning or otherwise.

"Sharing and discussion in the online environment worked well."

These responses indicated that the students deemed the course is suitable to be conducted online in which the students managed to interact well with both the lecturers and his/her peers virtually.

\section{Instructor Role Online}

The second dimension of the online learning design that corresponds with the findings is Instructor Role Online which refers the presence of the instructors in the teaching and learning process.

"Madam ... is someone is very nice to talk to and she is a very understandable lecturer when it comes to us. The way she interacts with us makes us excited to learn more and the way she taught is the simplest way but yet we understand what she is trying too deliver. We really hope we can meet Madam ... physically one day."

"In terms of interaction with lecturer and the delivery of course content, it was really good. The lecturer worked hard to provide us with all sorts of materials available in order to assist us to better understand the course. Aside from that, the lecturer gave a thorough feedback too for the assessments we have submitted. It certainly felt pleasant."

"This class was insightful and the lecturer was both approachable and communicative, not to mention extremely supportive and understanding towards their students."

"The lecturer is not actively responsive to her students' requests. This can be troublesome as students require constant guidance from their lecturers."

"The lecturer sometimes takes days, even more than a week, to reply messages. gave a guideline for one assessment, in a confusing way, and then decided to change it four weeks later."

Based on the responses derived, it shows that the instructors' presence plays an important role in online learning. When the instructors' presence is felt by the students, they would be more motivated and always look forward to the next lesson or session. On the other hand, irresponsive instructors tend to demotivate the students to the extent the students felt they 
have no one to guide them. This proves that in online learning environment, instructors' presence is of utmost importance to avoid students from drifting away from the courses they are taking or worse losing their motivation to study.

\section{Student Role Online}

The third dimension of the online learning design that corresponds with the findings is Student Role Online which refers to the tasks carried out by the students in the teaching and learning process.

"There were a few times when we'd fall into a misunderstanding but that's normal in group work. Overall, we had great team work and support from each other until the end of the project."

"From past experience of doing the company meeting assessment with assigned peers, it surely connected us in a comfortable atmosphere (even though we only got to see each other's faces). The experience of holding a group task together was fun and exciting. I genuinely enjoyed the time that me and my group members discussed and presented our thoughts and opinions through the video that we took together."

"With the many challenges we went through, our peer interaction with together was great as we sticked through together from the very beginning to the end."

The responses above depict the significance of the students' role in online learning by providing support to one another in completing their tasks for all courses taken. Having good interaction with each other and manage to cooperate well on a team would leave a positive perception on them depending on the nature of the group assessment or assignment.

\section{Pacing}

The fourth dimension of the online learning design that corresponds with the findings is pacing which ranges from Self-paced to Class-paced or a combination of both.

"Not take the full $2 \mathrm{hr}$ class and make it shorter."

"My lecturer is so understanding that she always gives us 5 to 10 minutes break!"

"Lecturer was very helpful even after class hours."

The above responses represent the students' perception that they could not cope with the classroom duration when teaching and learning is done online without any break in between. In addition, students found it pleasing if the instructors are willing to entertain them according their own, individual pace in learning, not the one set by their instructors.

\section{Pedagogy}

The fifth dimension of the online learning design that corresponds with the findings is pedagogy which refers to the teaching and learning approaches employed by the instructor.

"Our lecturer is very helpful. She guides us and assist us in making the project smooth and a success."

This response indicates that the instructors' approach of allowing the students to explore their project on their own with assistance from the instructor is favoured by the students. Other responses retrieved were:

"Lecturer could have interact more with students about homeworks and exercises on $i$ learn."

"Autonomous learning makes it hard for me to determine whether the delivery is excellent or not." 
Based on these responses, it clearly shows that students deem it is necessary for the instructor to employ approaches that allow them to have more interaction so the students will have the room to ask for any uncertainties they have for the subject they are taking. Additionally, one

of the respondents consider the presence of autonomous learning approach that requires students to be independent learners make it hard for him/her to evaluate the effectiveness or appropriateness of the approach employed by his/her instructors.

\section{Online Communication Synchrony}

The sixth dimension of the online learning design that corresponds with the findings is Online Communication Synchrony which refers to whether the instructor conducts synchronous, asynchronous or a blend of both in the teaching and learning process.

"The lecturer delivered the lesson very very well and i love how she always save the recorded version that i can watch when i want to do a revision."

This response indicates that there is a need for a blend of both synchronous and asynchronous sessions to ensure effective delivery.

"Materials are easily accessible and lecturer gave a detailed delivery of course content." "Powerpoint slides are needed during live classes to enhance students' knowledge and more live classes are needed."

"Save the previous classes to make sure that the ones who missed it and didnt have clear connection at the time can have the option to watch the whole class again."

"The lecturer rarely did live meet and postponed her classes almost every time. It's hard to learn in such condition. I hope this situation won't happen again in the future."

"Would like it if given access to materials after classes so it will be easier to review. Lecturer was great at delivering the course content."

The responses above depict the need for learning materials to be made accessible for students especially those with poor internet access to ensure they can retrieve these at their convenience. Materials can be in the forms of Power Point slides and recorded live sessions which the students are able to refer to anytime they need them. In general, having both synchronous and asynchronous sessions is favoured by students as they are able to comprehend the lesson delivered better and felt they have something to hold on to and someone present to clarify their uncertainties.

\section{Source of Feedback}

The final dimension of the online learning design that corresponds with the findings is Source of Feedback that refers to Automated, Teacher or Peer feedback.

"I hope that the lecturer could've make time to give feedbacks on our assignments so that we would be prepared for our assessments. I remember doing the digital portfolio as a practice and we needed to submit it. I was hoping that the lecturer would give comments on my answers and my format because I needed to know if I was on the right track or not otherwise at least give an example on how to answer all the digital portfolios."

This response shows that the students need feedbacks especially from their instructors to assist them with their tasks.

"The lecturers provided very useful feedback to improve the quality of our project."

"Madam is very responsive, gives feedback and suggests what to do and what not to do." 
The above are responses derived that indicate students value the feedbacks and suggestions provided by their instructor to ensure they are on the right path in completing their tasks and assignments.

"Excellent. Students often give opinions and inputs on the content given."

"Everyone has been checking up on each other throughout the learning process."

"I've received supports from my close friends and helps from them throughout this semester. We managed to discuss misunderstandings and confusions that occured during the whole learning process."

"Peers are helpful and supportive in sharing information about the assessments."

"My peers and friends gave me the help and support I needed."

The above responses depict that students believe that support and feedbacks received from their friends kept them going in online learning environment.

\section{Conclusion}

Thematic Analysis enables a close examination over large and rich data. With responses from 256 respondents for 25 courses and 2 dimensions, thematic analysis allows traceability and verification of analysis done against theories of online learning. Therefore, it is useful for curriculum designers and instructors to improve the existing online learning curriculum and practices while its benefits are for students to become better learners in online learning.

Though TA is a clear, uncomplicated, and straightforward qualitative study which does not need some theoretical details and technical knowledge such as discourse analysis or conversational analysis and, it can be said that doing a good TA in data is a simple, enjoying, and flexible work, like other qualitative methods, some potential pitfalls may result in weak analysis and has to be dealt with such as, unbiased in doing TA as a research work. Unprofessional and simplistic view sometimes destroys the value and validity of TA in a way that the result becomes desired and positive and thus leads to serious damage. Besides that, researcher should find out whether his/her interpretations and analytical points are compatible with the extracted data or not.

\section{Limitations and Future Studies}

The current study only explored one dimension of FOLC advocated by Van Oostveen (2016) which is the Social Presence. The other dimension that is the Cognitive Presence was not investigated. In addition, the analysis carried out were merely focusing on two constructs lecturers' delivery and peer interaction. There are other relevant constructs which can be looked into. Amongst them are course content and assessment. The researchers are attempting to analyse these different constructs to gain a better and clearer understanding of the changes and modifications that need to be done in carrying out the programme's first curriculum review in ensuring the LG120 language programme can be a full-fledged and wellrecognised academic programme. Future research interested may delve into the other dimension of FOLC - the Cognitive Presence to further see how the combination of both dimensions will materialise successful collaborative learning.

\section{References}

Blayone, T. J., Barber, W., DiGiuseppe, M., \& Childs, E. (2017). Democratizing digital learning: theorizing the fully online learning community model. International Journal of Educational Technology in Higher Education, 14(1), 1-16. 
Braun, V., \& Clarke, V. (2006). Using thematic analysis in psychology. Qualitative research in psychology, 3(2), 77-101.

Dulfer, N., McKernan, A., \& Brindle, K. (2017). Different countries, different approaches to teaching and learning?.

Jääskelä, P., \& Nissilä, P. (2015). Identifying themes for research-based development of pedagogy and guidance in higher education. Scandinavian Journal of Educational Research, 59(1), 24-41.

Javadi, M., \& Zarea, K. (2016). Understanding thematic analysis and its pitfall. Demo, 1(1), 3339.

Mukhtar, K., Javed, K., Arooj, M., \& Sethi, A. (2020). Advantages, Limitations and Recommendations for online learning during COVID-19 pandemic era. Pakistan journal of medical sciences, 36(COVID19-S4), S27.

Vaismoradi, M., Jones, J., Turunen, H., \& Snelgrove, S. (2016). Theme development in qualitative content analysis and thematic analysis.

Xu, W., \& Zammit, K. (2020). Applying thematic analysis to education: A hybrid approach to interpreting data in practitioner research. International Journal of Qualitative Methods, 19, 1609406920918810. 